\title{
Calculations on the STAR Conventional Magnet Design
}

\author{
T. Fornek*, H. Spinka, and D. Underwood \\ High Energy Physics Division
}

Argonne National Laboratory, Argonne, Ilinois 60439

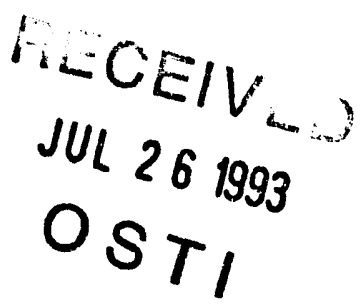

\section{June 1993}

\section{I) Introduction}

A thin superconducting solenoid magnet was originally planned for the STAR detector, as described in the Conceptual Design Report (CDR - Ref. 1). The electromagnetic calorimeter (EMC) was to be mounted outside the magnet coil and inside the magnet flux return in the form of iron bars. This design had relatively little coupling of the requirements for the magnet and the EMC.

After the CDR was written, it was decided to use a conventional solenoidal magnet with copper or aluminum coils instead, primarily on the basis of construction costs. The large thickness of coil material was expected to seriously degrade the calorimeter performance, so the coil was moved outside the EMC. In the process, the magnet and EMC designs became much more closely coupled. This note documents a variety of calculations related to this coupling, as well as some of the reasons for certain design parameters of both the electromagnetic calorimeter and the conventional solenoidal magnet.

\section{II) Constraints on the Magnet and Calorimeter Designs}

As noted above, a conventional magnet with aluminum or copper coils has been chosen for the present STAR design. To reduce manufacturing costs, the solenoidal coil will be constructed of a number of coil "pancakes". This permits the magnet to be segmented along its length. There are stringent requirements on the magnetic field uniformity for the operation of the $S T A R$ time projection chamber

* T. Fornek is on loan from Argonne's Engineering Physics Division. 
(TPC). These requirements translate into tight tolerances on the position of the individual pancakes $(\sim \mathrm{mm})$ along the solenoidal axis. There are less stringent tolerances $(\sim 5 \mathrm{~mm})$ on the deviations from a circle for each pancake, and on the radial positioning of the pancakes relative to each other.

The magnet coil is assumed to be supported from the magnet flux return bars. Each of these bars will be attached to the two iron end rings. In addition, the bottom bars will be connected to the large STAR detector supports. The cross sectional area of the magnet flux return bars is designed so that none of the iron will be in saturation when the magnet is at full field.

The magnet. inner radius is determined by the radius of the TPC, the thickness of the central barrel trigger counters and time-of-flight scintillation counters, and the height of the EMC. It has been estimated that an increase of $1 \mathrm{~cm}$ in radius would cost an additional $\$ 50 \mathrm{~K}$ for magnet construction (coil and magnet return flux bars) for a coil radius near the present design value. Thus the height of the EMC should be minimized. The magnet outer radius is loosely constrained by the dimensions of the experimental hall and the beam height, and by the height of the doorway into the hall.

The present magnet design has an inner radius of $2620 \mathrm{~mm}$, a distance between pole tips of $6200 \mathrm{~mm}$, and a total weight $\sim$ 1200-1300 tons. The overall length is about $7250 \mathrm{~mm}$ (steel to steel). The thirty magnet flux return bars will have cross sectional area of $508 \times 610 \mathrm{~mm}^{2}\left(20^{\prime \prime} \times 24 "\right)$ and a total weight of 500 tons. The magnet will be maintained near room temperature by chilled water cooling in order to minimize the impact of temperature changes on various detector components during startup as the magnet is energized. Possible changes to the magnetic field caused by thermal expansion of different parts of the magnet coil and support will also be minimized.

A sampling calorimeter constructed of alternating layers of lead and plastic scintillator was chosen for the STAR detector as a compromise of energy resolution and cost. The barrel calorimeter subtends $0 \leq \phi \leq 2 \pi$ and $-1 \leq \eta \leq 1$ in the present design. Light must be brought from the calorimeter scintillators to photomultipliers or other "photon transducers" in such a design. At this time, photomultipliers are assumed because of extensive experience and relatively low cost. However, standard photomultipliers are sensitive to magnetic fields and would have to be mounted outside the magnet flux return bars. Plastic optical fibers are assumed to connect the scintillators and the photomultipliers. These fibers permit flexibility in 
routing and require relatively small "dead regions" in the calorimeter because of their small cross section ( $1 \mathrm{~mm}$ diameter).

The planned design for the electromagnetic calorimeter consists of 120 identical modules of length $\sim 3 \mathrm{~m}$ along the beam direction. Each module consists of 20 lead absorber plates of $5 \mathrm{~mm}$ thickness and 21 scintillator tiles of $4 \mathrm{~mm}$ thickness. A $20 \mathrm{~mm}$ aluminum plate at the calorimeter inner radius and $30 \mathrm{~mm}$ aluminum plate at the outer radius are used to distribute the gravity loads from the lead more uniformly. In the present design, spacers of I-beam cross section maintain the spacing between the lead plates while separating adjacent scintillator tiles by only 1-2 $\mathrm{mm}$. A stainless steel strongback attached to the outside face of the $30 \mathrm{~mm}$ aluminum plate is required to prevent sizable deflections in the calorimeter modules. The total calorimeter weight is estimated to be $\sim 190$ tons.

In order to achieve good energy resolution with a sampling calorimeter, there must be adequate absorber thickness and sufficient light received at the photomultipliers. The absorber thickness is related to the height of the EMC, which affects the inner magnet radius and the magnet cost. The amount of transmitted light is dependent on the length of the optical fibers (attenuation length $\sim 6 \mathrm{~m}$ ) and on the path for the fibers to the photomultipliers. The path length would be about $7 \mathrm{~m}$ if the fibers were routed around the magnet coil ends to the photomultipliers mounted outside the magnet flux return bars. The path length and light attenuation can be substantially reduced if there are gaps between some of the coil pancakes, which also affects the magnet design.

In more detail, the height of the EMC is a sum of the thicknesses of the lead absorber, scintillator and I-beam spacers, and the structural material. Lead is a very common choice for EM calorimeters. The total absorber thickness must be at least 20 radiation lengths to contain essentially all of the shower energy for electrons or photons with energies up to tens of $\mathrm{GeV}$. There can be sizable fluctuations on the loss of shower energy from the outside radius of the calorimeter, which leads to a degradation of the EMC energy resolution. Reducing the scintillator thickness would reduce the light output and degrade the EMC energy resolution. Thus the height of the lead and scintillator stack for the EMC is somewhat fixed by physics requirements. However, the thickness of the structural material to support the weight of the lead is a function of the calorimeter support design. While the two aluminum plate thicknesses cannot be significantly reduced, the strongback thickness is a function of the allowed deflections and the distance between strongback supports. By segmenting the magnet coil and adding calorimeter supports, the 
strongback thickness can be reduced and the magnet radius reduced. As noted before, the magnet segmentation also reduces the fiber length, which improves the calorimeter resolution.

From detailed studies of fiber routing paths and lengths it was concluded that segmenting the magnet coil into ten equal sections would acceptably minimize light attenuation effects. Between each pair of magnet sections would be stainless steel or aluminum rings to support the calorimeter modules. The ring thicknesses were estimated to be $76 \mathrm{~mm}$, as described in the following section. In addition, a $51 \mathrm{~mm}$ gap for the fibers is adjacent to the support rings. Figure la shows a cross sectional view through the $76 \mathrm{~mm}$ ring and Fig. $1 \mathrm{~b}$ through the $51 \mathrm{~mm}$ gaps for the fiber routing. At the center of the magnet and calorimeter are two $51 \mathrm{~mm}$ rings with a single gap of $76 \mathrm{~mm}$. The combined dimensions of the ring thickness and gap are based on the minimum bending radius requirements for the optical fiber bundles. The ring spacing is $620 \mathrm{~mm}$ along the beam. It was unclear during this work whether the coils would be compressed against the rings, adding further loads to them.

\section{III) Analytical Calculations}

Several analytical calculations of stresses and deflections in the proposed calorimeter support rings were performed. The purpose was to evaluate whether 76 mm thick rings were sufficient to support the calorimeter and perhaps part of the magnet coil gravitational loads. Estimates of deflections in the rings were also of importance as these affect the tolerances that must be allowed between EMC modules. Note that gaps between modules are undesirable for physics since the calorimeter is not sensitive to particles traveling in the gaps.

A pair of calculations was performed for $76 \mathrm{~mm}$ thick rings of inner radius $2620 \mathrm{~mm}$ and outer radius $2970 \mathrm{~mm}$ supported only at the bottom. Low stresses were computed for either type 6061 aluminum or type 304 (nonmagnetic) stainless steel rings under gravitational load from the ring alone, as shown in Tables 1 and 2, respectively. Maximum deflections of $0.5-1.1 \mathrm{~mm}$ were estimated.

Considerably higher, but still acceptable, stresses were computed for gravitational loading from both the ring and the EMC modules. The load from the EMC was assumed to be $40380 \mathrm{lb}$. per ring, corresponding to a total electromagnetic calorimeter weight of 202 tons. This weight includes the stainless steel strongback. However, quite sizable maximum deflections were calculated. At the top of the rings, the estimated deflections were $16.5 \mathrm{~mm}$ and $6.4 \mathrm{~mm}$ for aluminum and stain-

less steel in Tables 1 and 2, respectively. 
These estimated deflections with the EMC gravitational loading included were judged to be unacceptable. To achieve acceptable deflections would require significantly thicker rings, which takes further space from the magnet coil. It was concluded that the rings would probably be adequate to support the EMC if they were supported at additional points from the magnet flux return bars. Finite element calculations of these same conditions are discussed in the next section.

An estimate of the stress and deflection in one magnet flux return bar was also performed. The bar dimensions were $508 \times 610 \times 6200 \mathrm{~mm}^{3}$, and the material was assumed to be type 1010 iron. A quite small deflection $(0.23-0.33 \mathrm{~mm})$ and very low stress (633 psi) were calculated, as shown in Table 3. The bar was taken to be uniform and simply supported at the ends. The deflection would be less if the bar were clamped at the ends to the end iron rings.

Finally, deflections and stresses in the magnet flux return bars with gravity loading of the bars, EMC support rings, electromagnetic calorimeter, magnet coil, and the TPC were computed. The total weight of the aluminum rings, EMC, copper coil, and TPC were assumed to be $26,700,371,000,400,000$, and 48,000 lb., respectively. In one case the loading was applied uniformly to the 30 bars, and in the other case the coil load only was divided equally among the seven bars at the bottom while the other loads were uniform. For both cases, the bars were taken to be simply supported. The results are presented in Table 3, where it can be seen that the stresses are low $(<2000 \mathrm{psi})$ and the deflections are $\leqslant 1 \mathrm{~mm}$.

\section{IV) Finite Element Calculation}

The majority of the stress and deflection calculations performed for the EMC support rings and the magnet flux return bars used the inite element code ALGOR (SSAP04 version, dated 2/25/91) running on a 486-33 personal computer. The hard disk space available to this program was $90 \mathrm{Mb}$. The results are summarized in Tables 1, 2, and 3 along with the name of the model for reference. These calculations typically took $0.25-1.0$ hours to complete.

The electromagnetic calorimeter support rings were first studied independent of the magnet flux return bars. The rings were modeled with plate elements of thickness $3^{\prime \prime}=76 \mathrm{~mm}$. The ring inner radius was $2620 \mathrm{~mm}$ and the outer radius was $14 "=356 \mathrm{~mm}$ larger. The rings were supported from the bottom only for most of the cases considered. Gravity loads for the ring alone and for the combined ring and EMC were evaluated, and the results for aluminum and stainless steel rings 
are given in Tables 1 and 2, respectively. Good agreeinent with analytical estimates is observed for deflections. However, the computed maximum stress is always lower by approximately $27 \%$ for the finite element calculations. Differences of such magnitude are considered typical and are related to the finite size of the elements and the complexity of the model. As a test of this statement, the finite element model HEPCOM8G from Table 1 was reanalyzed with a finer grid of elements. The maximum stress was found to be $673 \mathrm{psi}$, much closer to the analytical value. Furthermore, a calculation with a more recent version of ALGOR containing improved plate elements resulted in stresses very close to the analytically calculated values.

Figure 2 shows the stress within an aluminum ring with gravitational loading from both the ring (total weight $2870 \mathrm{lb}$ /ring) and the EMC (total weight $40380 \mathrm{lb} /$ ring). The finite element mesh shown for the ring is typical for all the models in Tables 1 and 2.

In one design option, the TPC is supported from the last EMC ring to minimize the TPC support length. In this design, the TPC supports are near 3 and 9 o'clock at each end of the TPC, and the gravitational load is approximately 12,000 lb. per support. The impact on the EMC support ring's deflection and stress from these additional loads was also considered; see Tables 1 and 2 . With the ring supported only at the bottom, both the maximum stress and deflections increase by over 50\% compared to the cases without the TPC. Figure 3 shows the stresses for the aluminum ring with the TPC. Both the stress and deflections are significantly reduced when the EMC support ring is supported from the top and bottom as shown in Table 1 and Figure 4. For comparison, Fig. 5 shows the same case as Fig. 4, but without the TPC loading.

A model of the magnet flux return bars was studied with finite volume elements as shown in Fig. 6. Deflections and stresses are symmetric about the center plane of the STAR detector and also about a vertical plane containing the beam. Thus only half the bars were considered, and only half of the bar length was modeled with the appropriate constraints. One end of each bar was assumed to be simply supported, and the other end was constrained to remain in a vertical plane. The effects of gravity loading from the bars and from the EMC were computed. The stresses are shown in Fig. 6. After studying this model, it was concluded that it was too complex to add the rings and EMC for the available computer system; a smaller number of elements would be required to represent the magnet flux return bars in order to keep computation time less than several hours. 
The interaction of the gravitational loads from the magnet flux return bars, the EMC support rings and the calorimeter was studied using an extension of the finite element model of the rings described above. The same plate elements and mesh were employed for each ring. The magnet flux return bars were modeled with beam elements attached in 30 locations to each aluminum ring with beam elements. The bending moments of the beam elements representing the bars were computed by ALGOR for the actual orientation of the bars around the STAR detector. The bars were assumed to be constructed of type 1010 iron and to have dimensions 610 $\mathrm{mm}$ radially, $6200 \mathrm{~mm}$ along the solenoida! magnet axis, and $508 \mathrm{~mm}$ around the circumference. The length of the beam elements connecting the bars to the rings was chosen to give the distance between the bar center to the outer diameter of the aluminum rings. These beam elements were assumed to have the same mechanical properties as the iron bars, but zero mass. Similar beam elements connected the inner ring diameter to gravity loads from the 60 electromagnetic calorimeter modules $(673 \mathrm{lb}$. per ring per module, except the ring at the center of the STAR detector). Figure 7 and Table 3 contain the stresses and deflections for the rings and bars with gravity loads from the bars, rings, and EMC.

Two additional cases were considered, as modifications to the model described above. One included the TPC as point loads at the inner edge of the end EMC support ring; the loads were located at 3 and 9 o'clock. The second case added the TPC and increased the EMC loads to simulate gravitational loads from the magnet coils. The revised loads were 2.1 times the EMC values, or a total of $1413 \mathrm{lb}$. per ring per module and total magnet weight of $\sim 222$ tons. The stresses and deflections for the second case are given in Table 3 and Fig. 8. The maximum deflections are small for all cases considered since the rings are connected to each of the magnet flux return bars.

Finally, the loads transmitted from the magnet flux return bars to the end iron rings can be estimated from the ALGOR finite element program. These loads are given in Fig. 9 for the case with the loads from the electromagnetic calorimeter and aluminum support rings, the magnet flux return bars, and the magnet coils attached to the rings (not including the TPC). These loads are based on simple support type connections between the flux return bars and the magnet end ring. This information was used for the conceptual design of the magnet and STAR supports. 


\section{V) Conclusions}

Various calculations were performed of the magnet flux return bars, the electromagnetic calorimeter and its support rings, the conventional magnet coils, and the time projection chamber. Simple checks of finite element models with analytical estimates generally gave good agreement for deflections, but differences of up to $30 \%$ in the maximum stresses. These differences in the stresses were determined to be the result of the large elements used to represent the rings and bars.

It was concluded that $3 "=76 \mathrm{~mm}$ aluminum or stainless steel rings supported at the bottom only could support loads from the EMC, TPC, and magnet coils, but that the deflections were unacceptably large, even with loads from the EMC alone. Considerably thicker rings would be required, but this would interfere with the magnet design. Thus, the rings would need additional supports from the upper magnet flux return bars.

If the rings are supported from each of the magnet flux return bars, stresses and deflections in the bars and rings are small for all loading cases considered. Thus, it should be possible to somewhat reduce the ring thickness, subject to constraints imposed by routing the EMC optical fibers.

\section{Acknowledgements}

We wish to thank Ed Bielick, Ralph Brown, Bill Edwards, Ken Foley, Jim Mills, Joseph Rasson, and Roger Stone plus members of the Argonne HEP and EP Divisions for useful discussions concerning the magnet, EMC, and TPC. The work of Ted Kicmal on some of the figures is gratefully acknowledged. This work was supported by the U. S. Department of Energy, Division of High Energy Physics, Contract W-31-109-ENG-38 and by R\&D funding for the RHIC project.

\section{Reference}

1) "Conceptual Design Report for the Solenoidal Tracker at RHIC", Lawrence Berkeley Laboratory Report PUB-5347, (1992). 


\section{Table 1}

\section{Stresses and Deflections Estimated for $76 \mathrm{~mm}$ Thick Aluminum Support Rings for the EM Calorimeter}

(Names for the finite element models are included (HEPCOM8i). The vertical deflection at the top is VTOP, the horizontal deflection at 9 o'clock is $\mathrm{H}_{\text {SIDE, }}$, etc.)

\begin{tabular}{|c|c|c|c|}
\hline Model & Supports & $\begin{array}{l}\text { MAX Stress } \\
\text { (psi) }\end{array}$ & Deflections \\
\hline $\begin{array}{l}\text { Ring under gravity load } \\
\text { (analytical) }\end{array}$ & $1 @ 6$ o'clock & 779 & $\begin{aligned} \mathrm{V}_{\text {TOP }}=0.043^{\prime \prime} \\
\mathrm{H}_{\text {SIDE }}=0.020^{\prime \prime}\end{aligned}$ \\
\hline $\begin{array}{c}\text { Ring under gravity load } \\
\text { (finite element, HEPCOM8G) }\end{array}$ & 1 (1) 6 o'clock & 574 & $\begin{array}{l}V_{\text {TOP }}=0.041^{\prime \prime} \\
V_{\text {SIDE }}=0.024 " \\
\text { HSIDE }=0.018^{\prime \prime}\end{array}$ \\
\hline $\begin{array}{c}\text { Ring + EMC under gravity } \\
\text { load (analytical) }\end{array}$ & $1 @ 6$ o'clock & 11900 & $\begin{array}{l}\mathrm{V}_{\text {TOP }}=0.65^{\prime \prime} \\
\mathrm{H}_{\text {SIDE }}=0.30^{\prime \prime}\end{array}$ \\
\hline $\begin{array}{c}\text { Ring + EMC } \\
\text { (finite element, HEPCOM8C) }\end{array}$ & 1 (1) 6 o'clock & 8800 & $\begin{aligned} V_{\text {TOP }} & =0.62 " \\
V_{\text {SIDE }} & =0.37^{\prime \prime} \\
H_{\text {SIDE }} & =0.28 "\end{aligned}$ \\
\hline $\begin{array}{c}\text { Ring + EMC + TPC } \\
\text { (finite element, HEPCOM8X) }\end{array}$ & $1 @ 6$ o'clock & 14000 & $\begin{array}{l}V_{\text {TOP }}=0.96^{\prime \prime} \\
V_{\text {SIDE }}=0.59^{\prime \prime} \\
\text { H }_{\text {SIDE }}=0.45^{\prime \prime}\end{array}$ \\
\hline $\begin{array}{c}\text { Ring + EMC + TPC } \\
\text { (finite element, HEPCOM8A) }\end{array}$ & $\begin{array}{l}1 \text { (1) o'clock } \\
1 \text { @ } 12 \text { o'clock }\end{array}$ & 4775 & $\begin{array}{l}V_{\text {MAX }}=0.13^{\prime \prime} \\
\text { @ 7:30 o'clock } \\
\\
H_{\text {MAX }}=0.06 " \\
\text { @ 7:30 o'clock }\end{array}$ \\
\hline $\begin{array}{c}\text { Ring + EMC } \\
\text { (finite element, HEPCOM8Y) }\end{array}$ & $\begin{array}{l}1 @ 6 \text { o'clock } \\
1 @ 12 \text { o'clock }\end{array}$ & 2840 & $\begin{array}{l}V_{\mathrm{MAX}}=0.07^{\prime \prime} \\
\text { @ 7:30 o'clock } \\
\\
\mathrm{H}_{\mathrm{MAX}}=0.03^{\prime \prime} \\
@ 7: 30 \text { o'clock }\end{array}$ \\
\hline
\end{tabular}




\section{Table 2}

Stresses and Deflections Estimated for $76 \mathrm{~mm}$ Thick Stainless Steel Support Rings for the EM Calorimeter

(Names for the finite element models are included (HEPCOM8i). The vertical

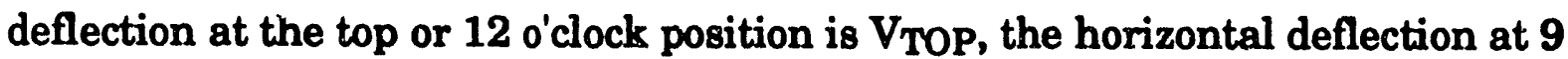
o'clock is HSIDE, etc.)

\begin{tabular}{|c|c|c|c|}
\hline Model & Supports & $\begin{array}{l}\text { MAX Stress } \\
\text { (psi) }\end{array}$ & Deflections \\
\hline $\begin{array}{l}\text { Ring under gravity load } \\
\text { (analytical) }\end{array}$ & 1 (1) 6 o'clock & 2334 & $\begin{array}{r}\mathrm{V}_{\text {TOP }}=0.043^{\prime \prime} \\
\mathrm{H}_{\text {SIDE }}=0.020^{\prime \prime}\end{array}$ \\
\hline $\begin{array}{c}\text { Ring under gravity load } \\
\text { (finite element, HEPCOM8E) }\end{array}$ & 1 @ 6 o'clock & 1664 & $\begin{array}{l}V_{\text {TOP }}=0.042^{\prime \prime} \\
V_{\text {SIDE }}=0.025^{\prime \prime} \\
\text { H }_{\text {SIDE }}=0.019^{\prime \prime}\end{array}$ \\
\hline $\begin{array}{c}\text { Ring + EMC under gravity } \\
\text { load (analytical) }\end{array}$ & 1 @ 6 o'clock & 13430 & $\begin{array}{l}\mathrm{V}_{\text {TOP }}=0.25^{\prime \prime} \\
\mathrm{H}_{\text {SIDE }}=0.12^{\prime \prime}\end{array}$ \\
\hline $\begin{array}{c}\text { Ring + EMC } \\
\text { (finite element, HEPCOM8D) }\end{array}$ & 1 @ 6 o'clock & 9800 & $\begin{aligned} V_{\text {TOP }} & =0.25^{\prime \prime} \\
V_{\text {SIDE }} & =0.15^{\prime \prime} \\
\mathrm{H}_{\text {SIDE }} & =0.11^{\prime \prime}\end{aligned}$ \\
\hline $\begin{array}{c}\text { Ring + EMC + TPC } \\
\text { (finite element, HEPCOM8B) }\end{array}$ & 1 (1) 6 o'clock & 14940 & $\begin{array}{l}V_{\text {TOP }}=0.37^{\prime \prime} \\
V_{\text {SIDE }}=0.22^{\prime \prime} \\
\text { HSIDE }=0.17^{\prime \prime}\end{array}$ \\
\hline
\end{tabular}




\section{Table 3}

\section{Stresses and Deflections Estimated for Magnet Flux Return Bars and Support Rings for the Electromagnetic Calorimeter}

(For these models, the magnet flux return bars are assumed to be simply supported and type 1010 iron, and the EMC support rings to be type 6061 aluminum. Names for the inite element models are included (HEPCOM6, etc.).

\begin{tabular}{|l|c|c|c|}
\hline \multicolumn{1}{|c|}{ Model } & \multicolumn{2}{|c|}{ Maximum Stresses } & $\begin{array}{c}\text { Marimum } \\
\text { (PSI) }\end{array}$ \\
Bar Deflection \\
\hline $\begin{array}{l}\text { Bars only under gravity load (analytical) } \\
\text { - Strong orientation } \\
\text { - Weak orientation }\end{array}$ & 527 & -- & $0.009 "$ \\
\hline $\begin{array}{l}\text { Bars and rings under gravity load (finite } \\
\text { element, HEPCOM6) }\end{array}$ & 633 & -- & $0.013^{\prime \prime}$ \\
\hline $\begin{array}{l}\text { Bars and uniform load from EMC, TPC, } \\
\text { and rings (analytical) } \\
\text { - Coil load on all 30 iron bars } \\
\text { - Coil load on bottom 7 iron bars }\end{array}$ & & & \\
\hline $\begin{array}{l}\text { Bars, rings, and uniform gravity load for } \\
\text { EMC (finite element, HEPCOM9) }\end{array}$ & 1139 & - & $0.012^{\prime \prime}$ \\
\hline $\begin{array}{l}\text { Bars, rings, TPC, and uniform load for } \\
\text { EMC (finite element, HEPCOM10) }\end{array}$ & 1880 & -- & $0.024 "$ \\
\hline $\begin{array}{l}\text { Bars, rings, TPC, and uniform load for } \\
\text { EMC and magnet coils (finite element, } \\
\text { HEPCOM11) }\end{array}$ & 1563 & 2030 & $0.041^{\prime \prime}$ \\
\hline
\end{tabular}




\section{FIGURE CAPTIONS}

1) a) Cross sectional view through the aluminum rings, EM calorimeter modules, and iron flux return bars. b) The same view through the spacers and gaps for optical fiber routing.

2) Stresses within an aluminum ring, with gravitational loads from the ring and EMC, from a finite element model (HEPCOM8C). The ring is supported only at the bottom.

3) Stresses within an aluminum ring with gravitational loads from the ring, EMC, and TPC (HEPCOM8X). The ring is supported only at the bottom.

4) Stresses within an aluminum ring with gravitational loads from the ring, EMC, and TPC (HEPCOM8A). The ring is supported at both the top and bottom.

5) Stresses within an aluminum ring with gravitational loads from the ring and EMC (HEPCOM8Y). The ring is supported at both the top and bottom.

6) Stresses within the magnet flux return bars from a finite element model (HEPMOD6).

7) Stresses in the (a) rings and (b) bars with gravitational loads from the bars, ring, and EMC (HEPCOM9).

8) Stresses in the (a) rings and (b) bars with gravitational loads from the bars, ring, magnet, TPC, and EMC (HEPCOM11).

9) (a) Horizontal and (b) vertical loads transmitted to the end iron rings from the magnet flux return bars with loads from the bars, aluminum rings, EMC, and magnet coils. 


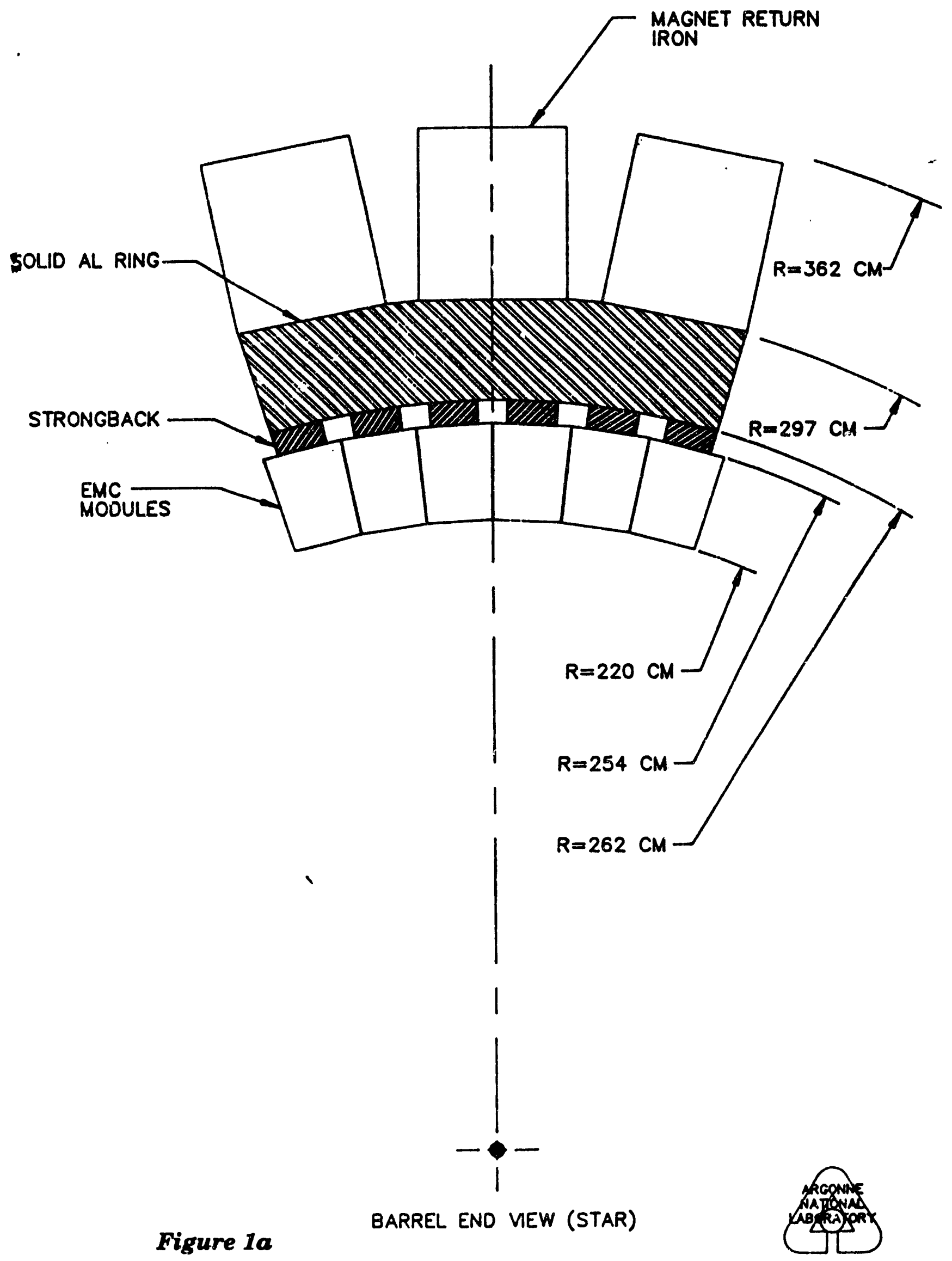




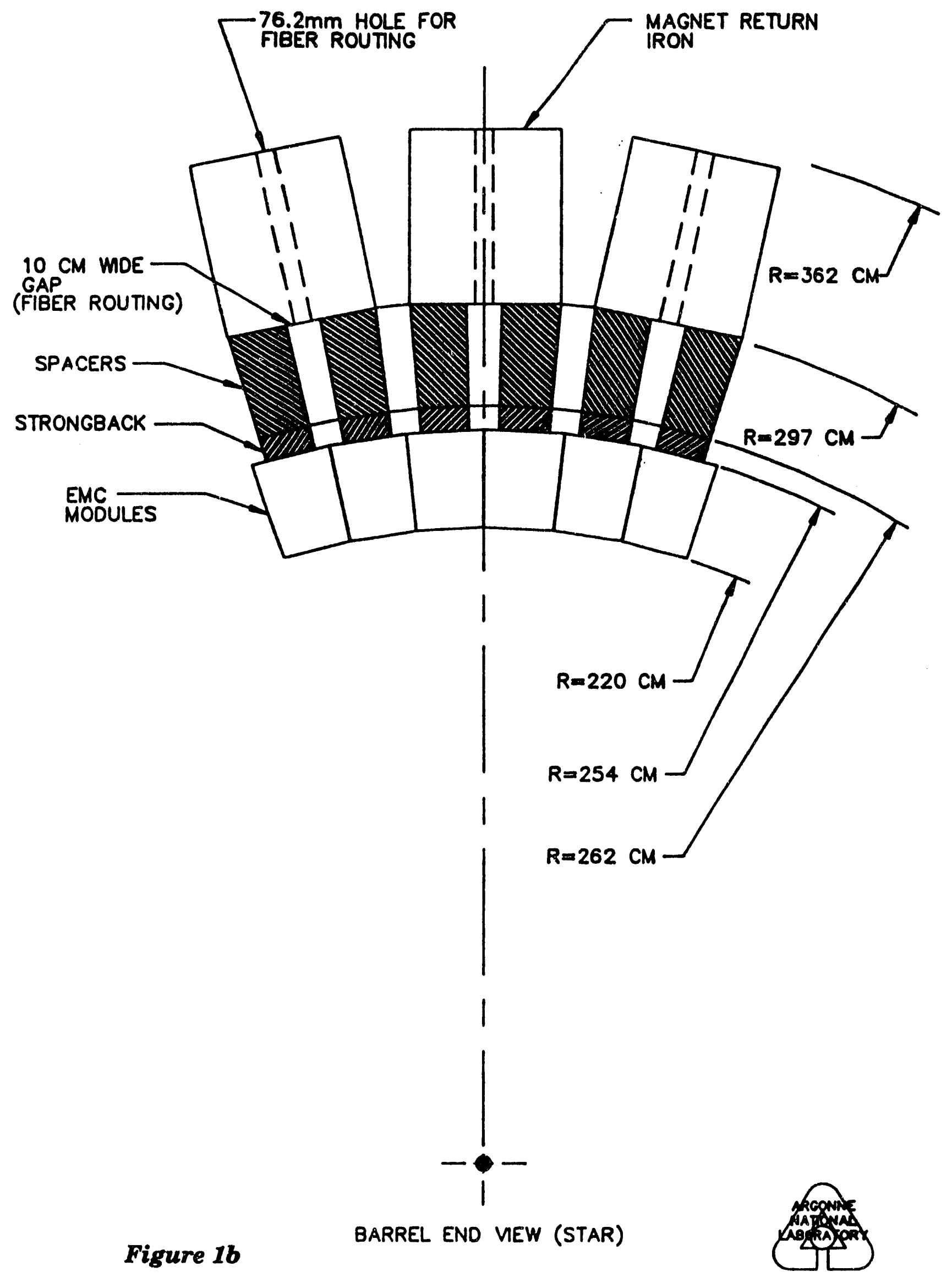



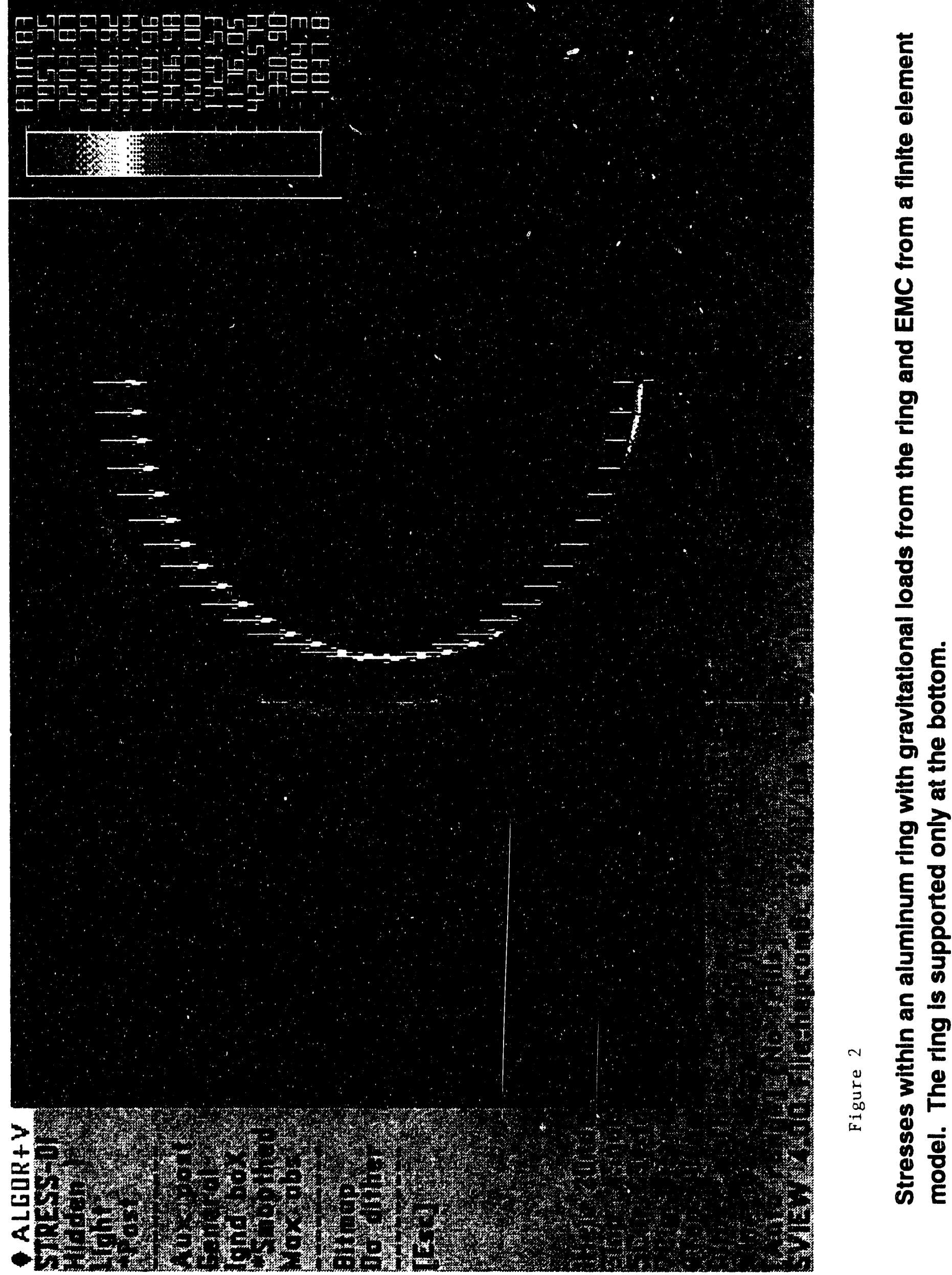

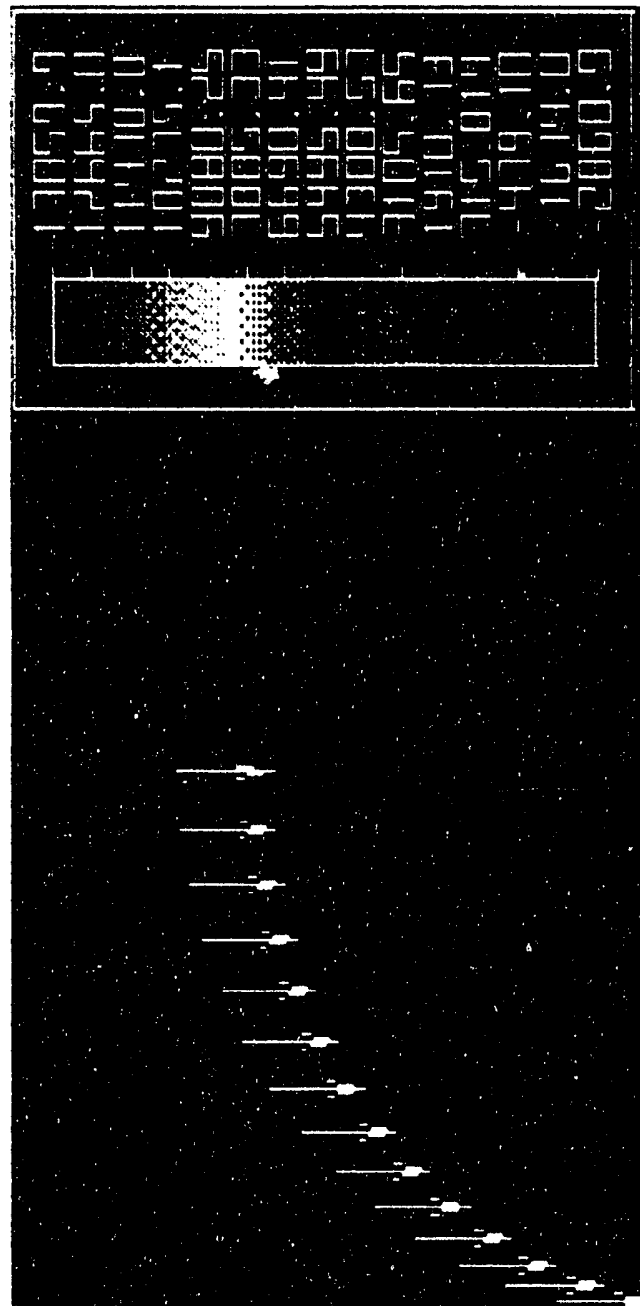

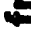

6

\%

으

$\overline{\mathbf{w}}$

ธ

응

$\stackrel{5}{2}$

iv

이

$=$

E

통






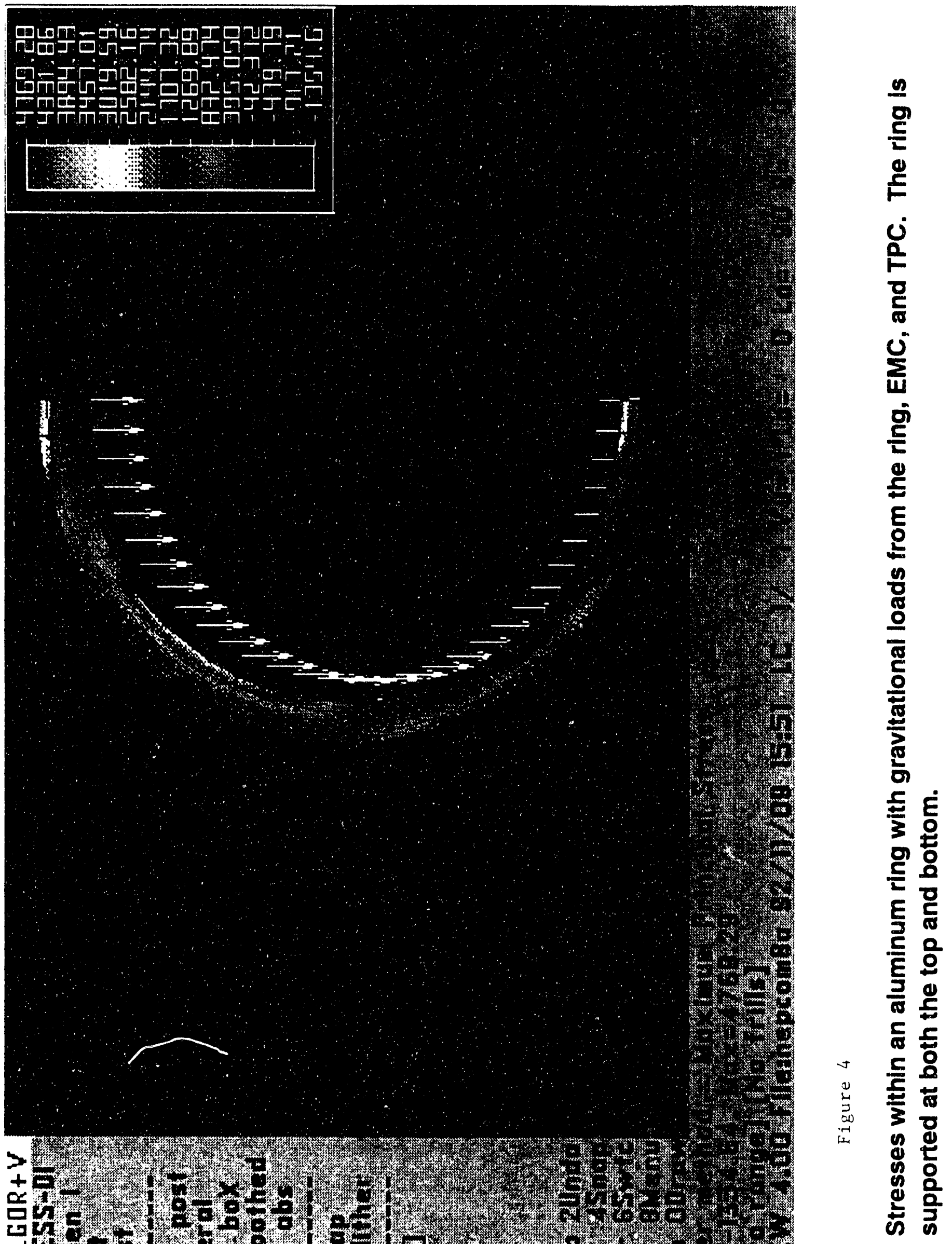

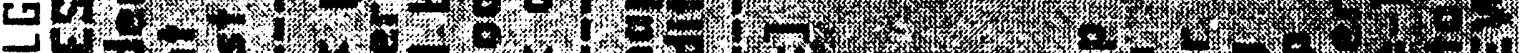

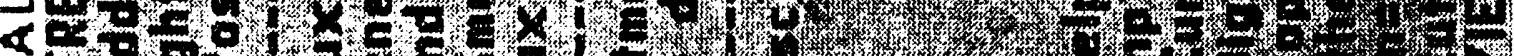

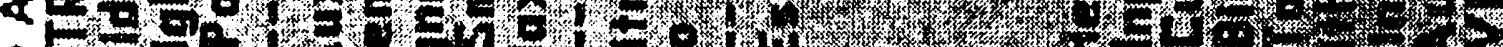

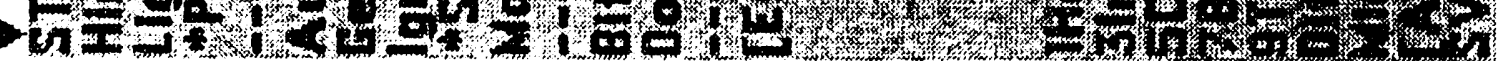




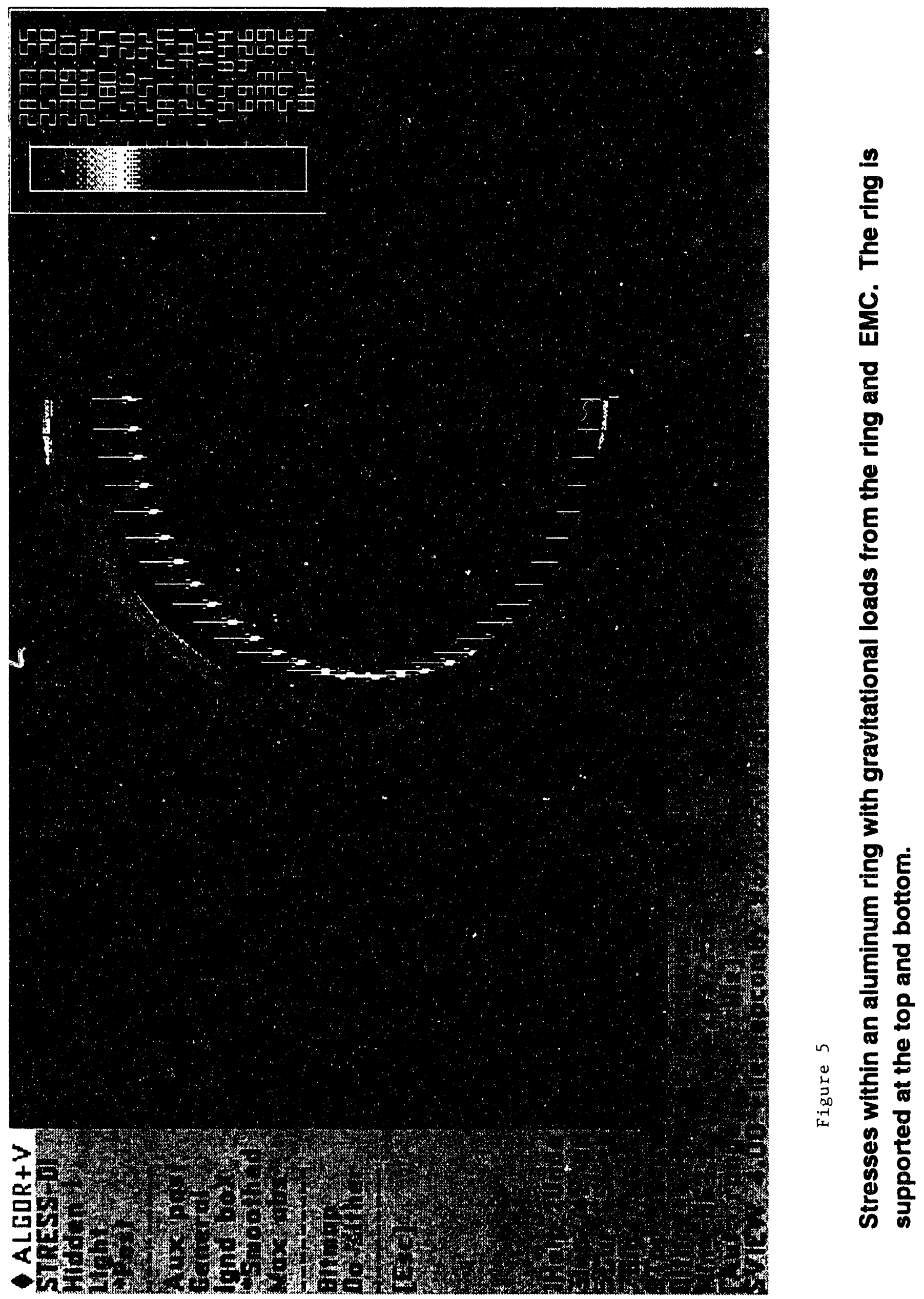




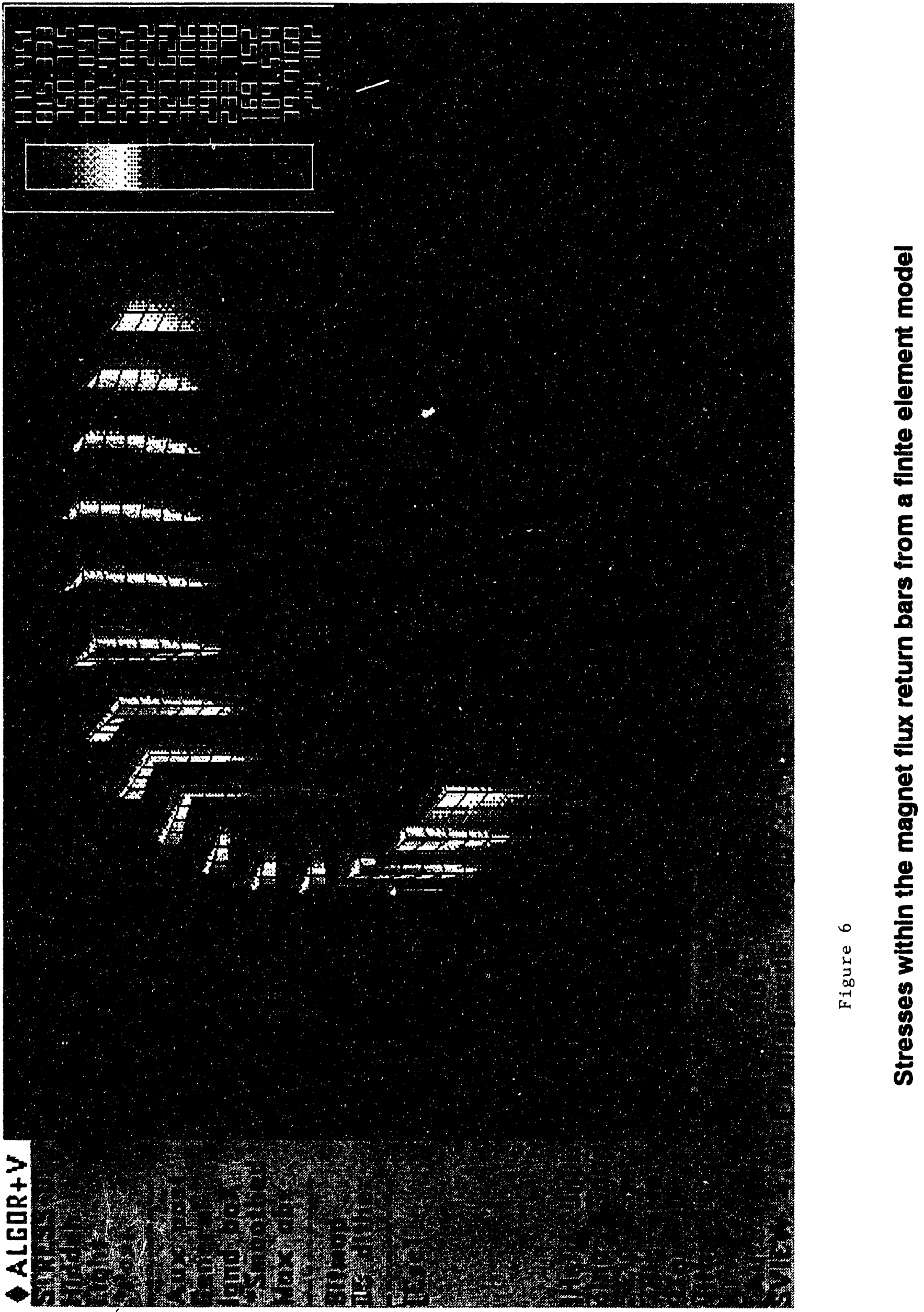




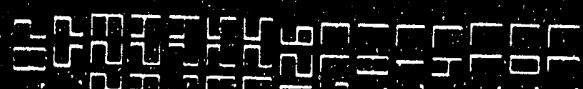

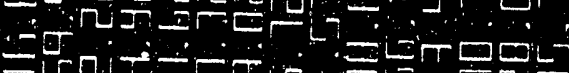

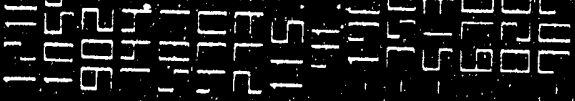
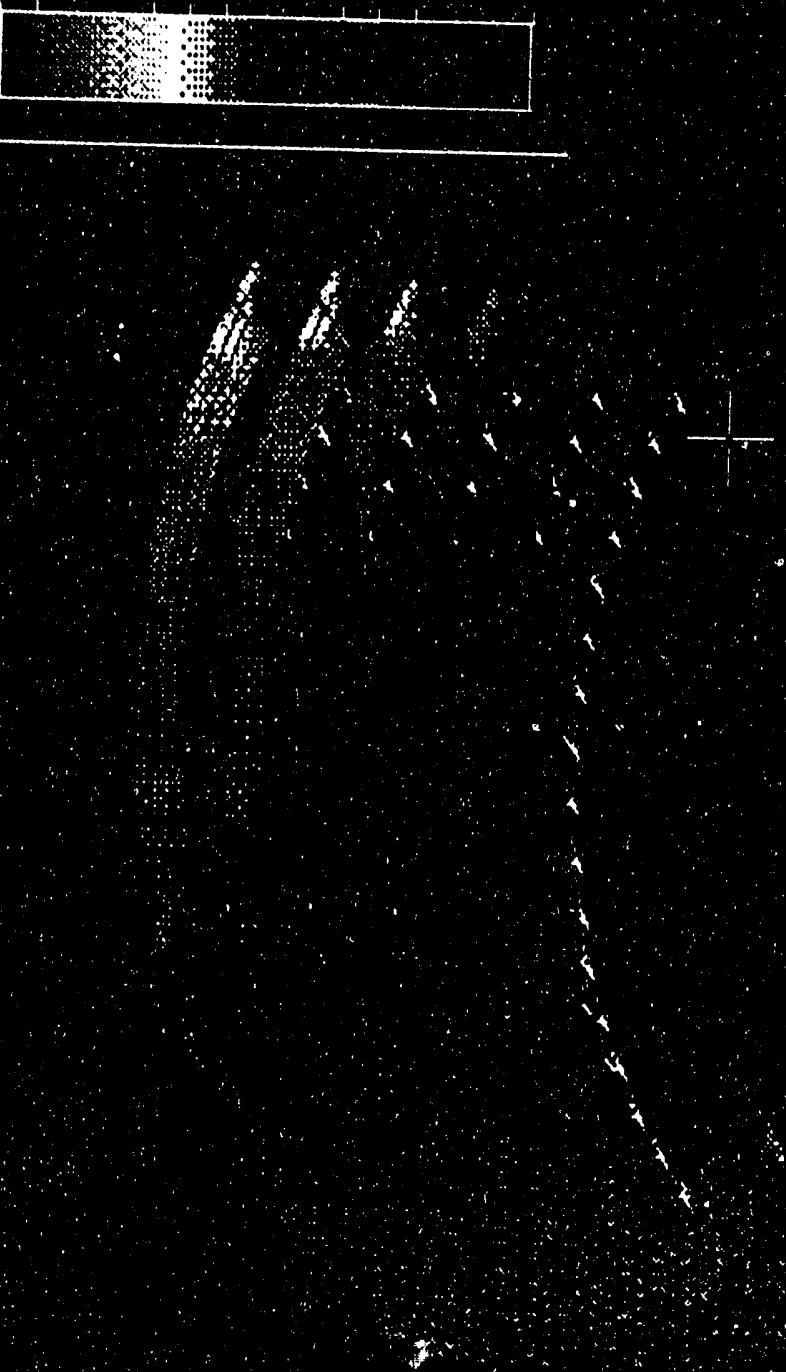

g

-

I

논

का 


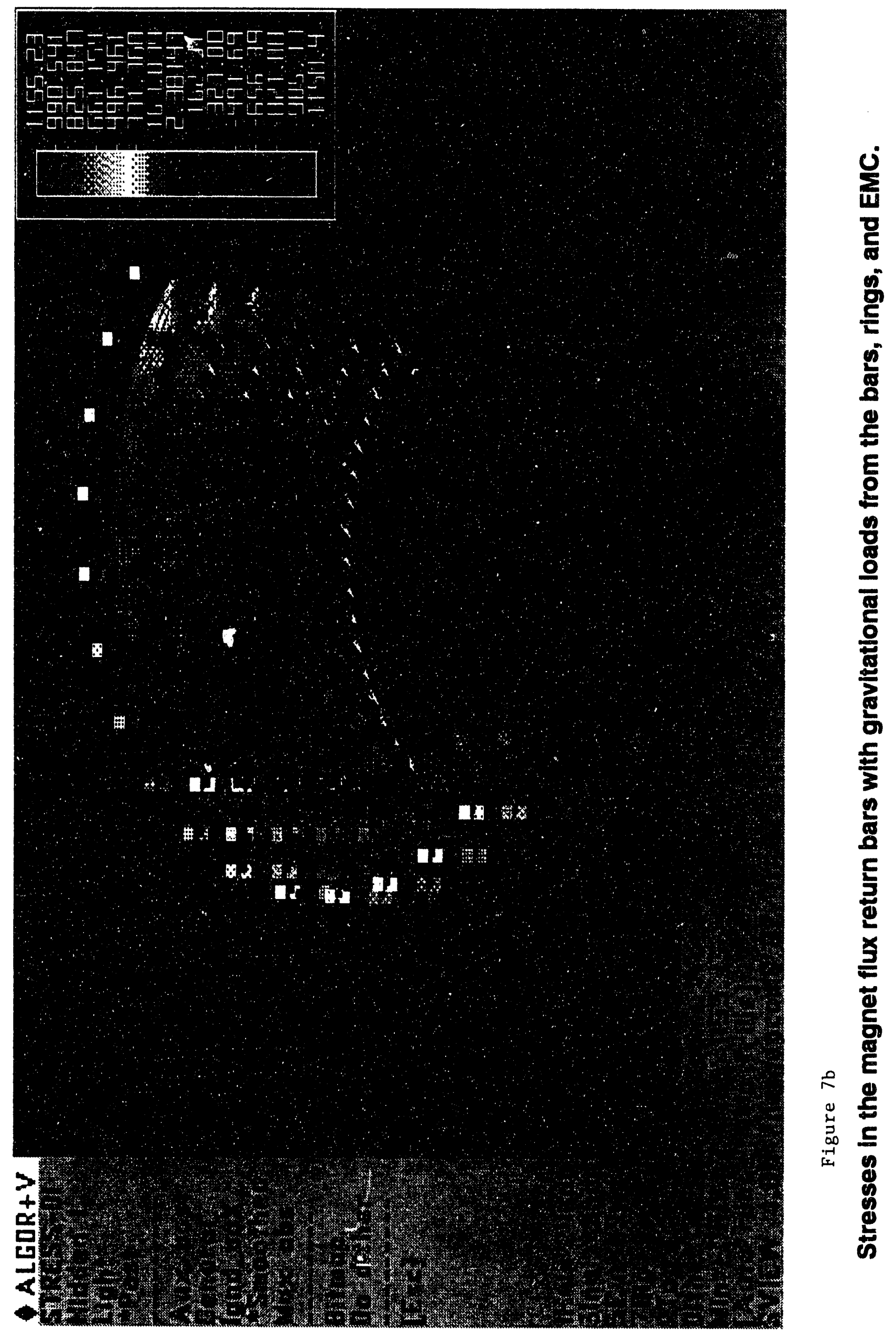




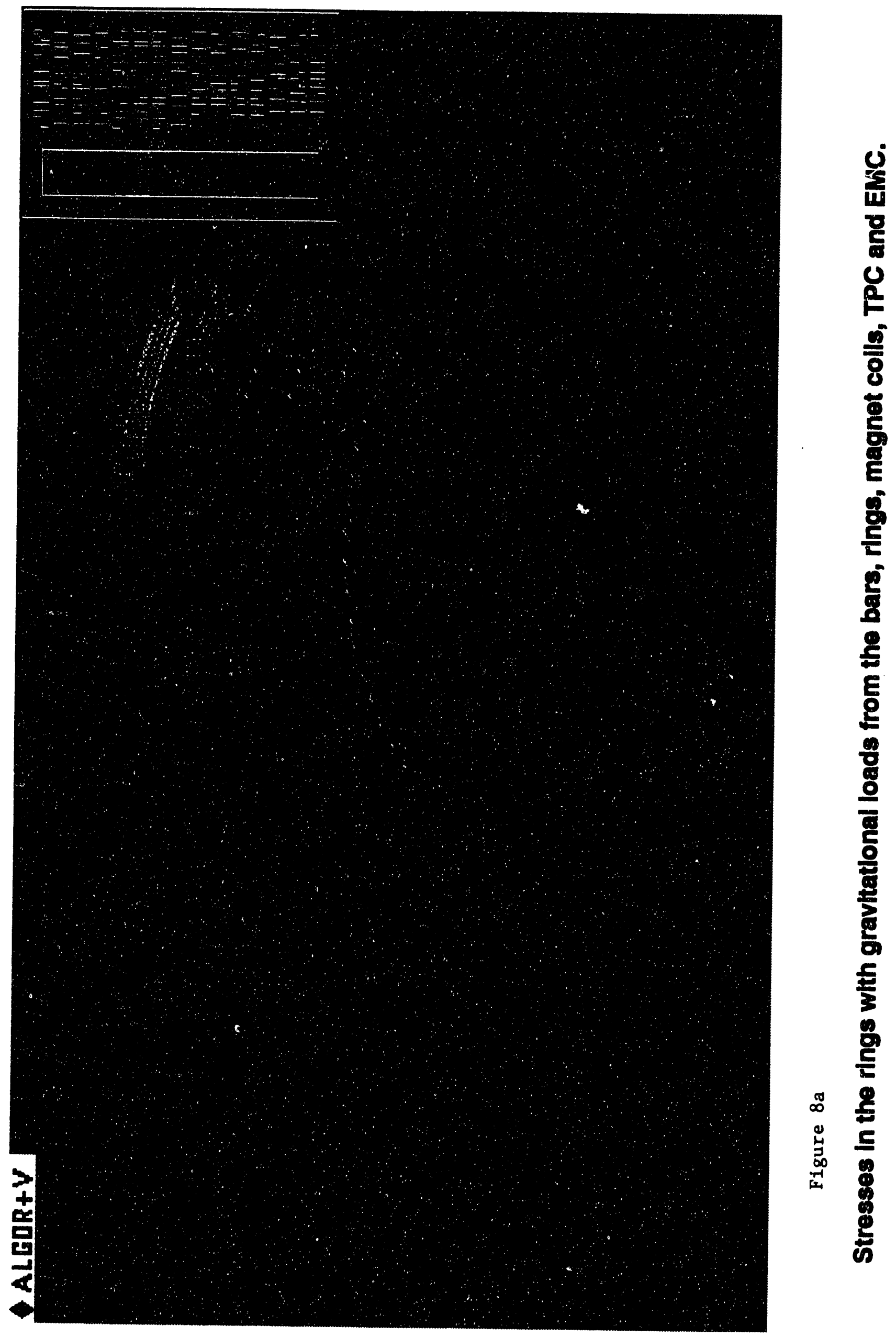



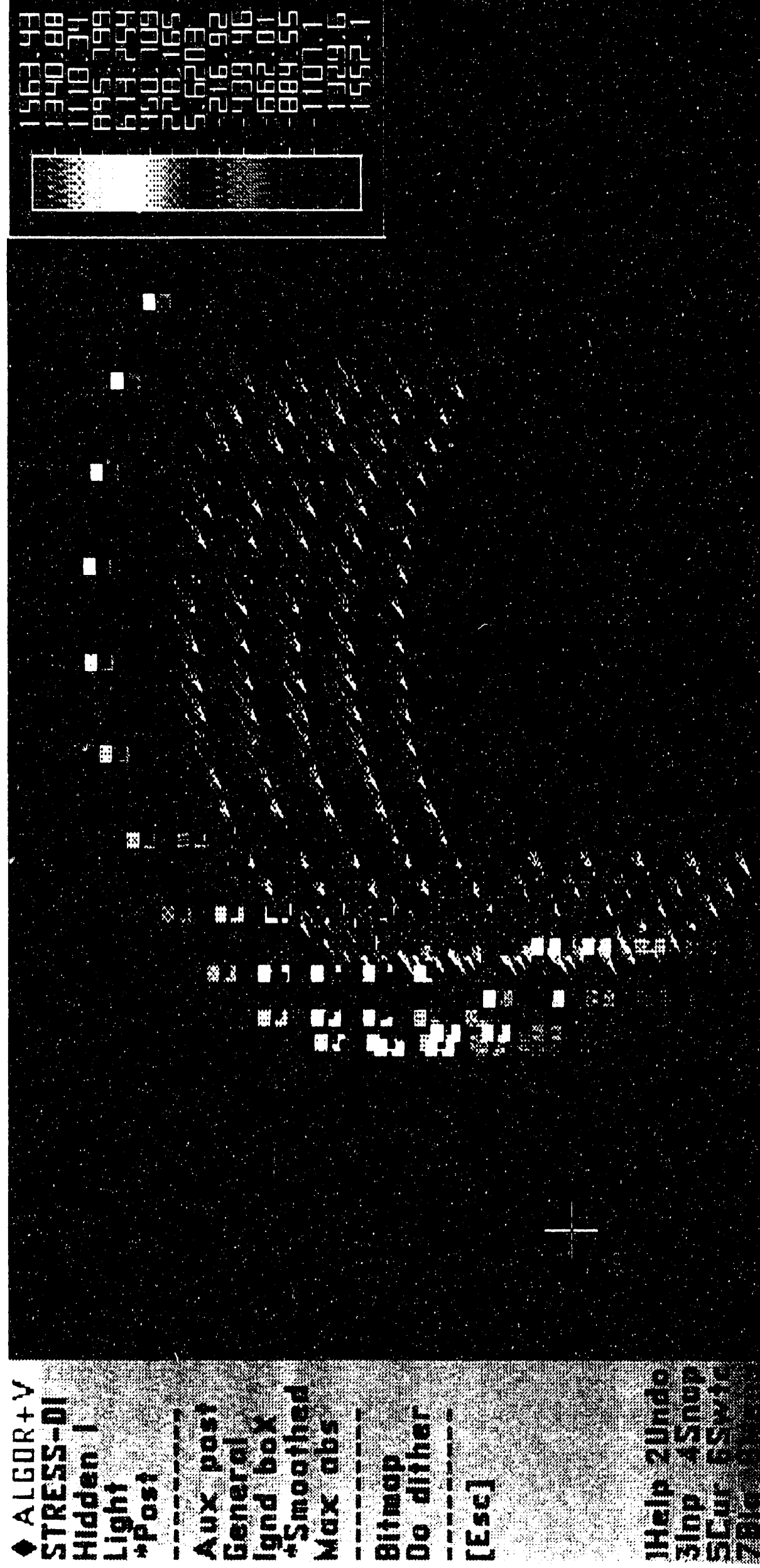


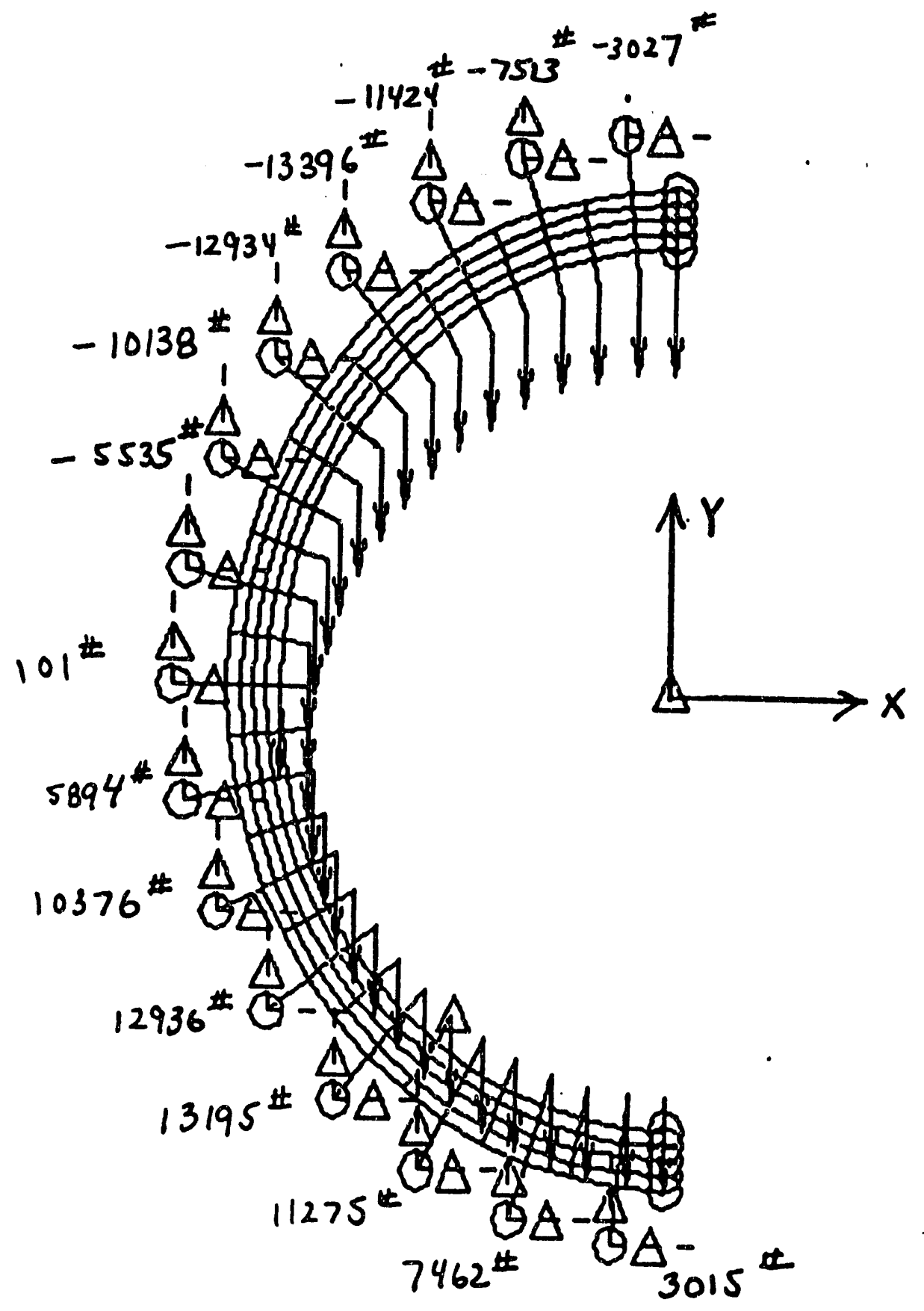

Figure 9a

$\mathrm{X}$-direction forces due to return iron and ring deadweight, plus EMC and coils. (Model HCOM 12) 


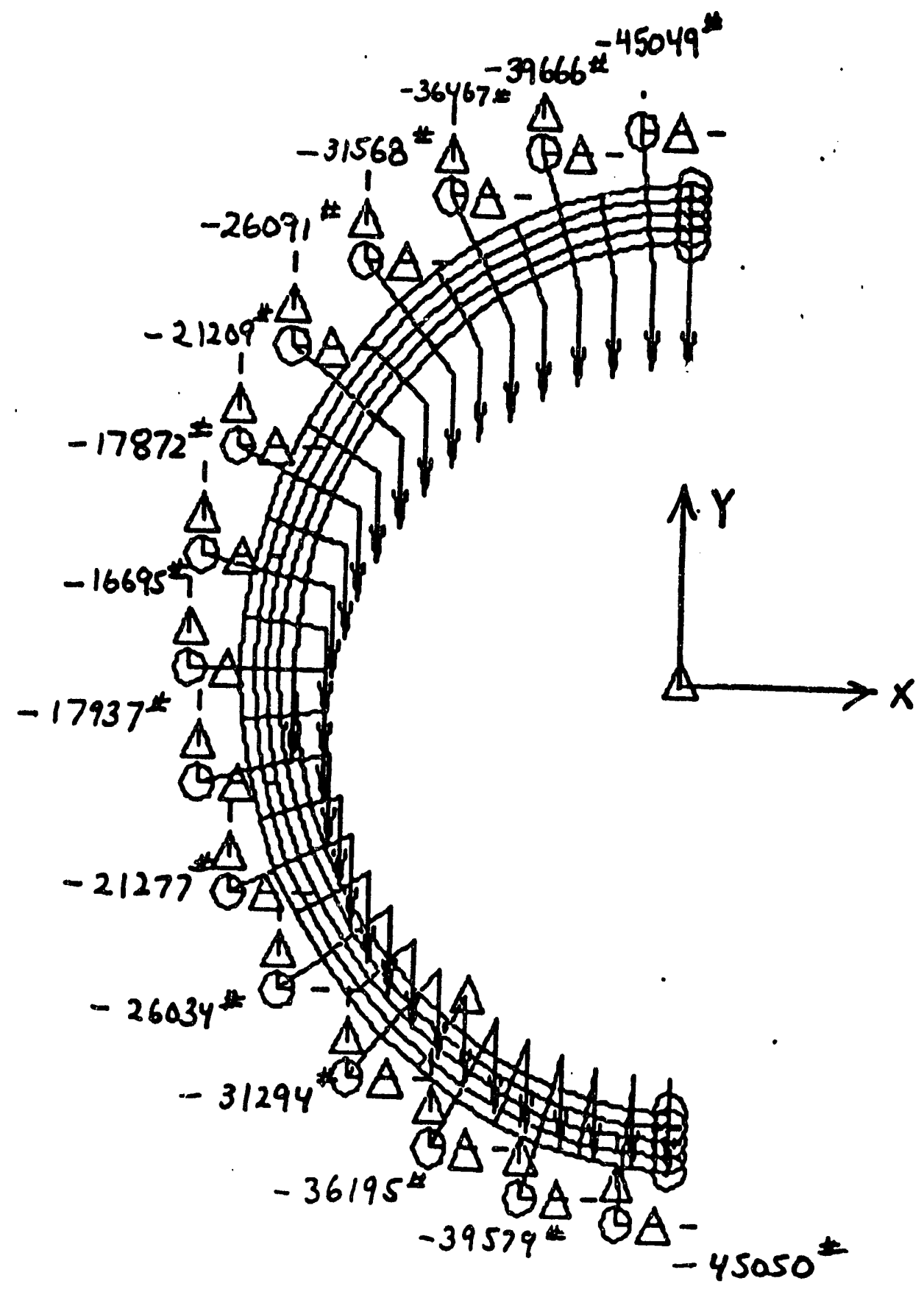

TUTAL LOAD is $-451983^{\#}$

Figure $9 b$

Y-direction forces due to return iron and ring deadweight, plus EMC and coils. (Model HCOM 12) 


\title{
Calculations on the STARR Convential Magnet Design Review Cover Sheet
}

\author{
T. Fornek*, H. Spinka, and D. Underwood
}

High Energy Physics Division

Argonne National Laboratory, Argonne, Illinois 60439

19 February 1993

Reviewed By: Date: $4 / 10 / 90$

Comments:

This paper provides an excellent baseline understanding and appreciation for the load interaction of the Electromagnetic Calorimeter (EMC) with the Conventional Magnet Core. Calculations using Finite Element Analys is with analytical checks based on Roark \& Young models for various loads and constraint scenarios, are presented. These scenarios are tabulated with their respective maximum stress and deflection. I have found the results of these calculations to be correct based on the following:

1) I reviewed the FEA models and analytical calculations and agree with the approach and methodology used to produce these results.

2) I performed an independent FEA analys is on the STAR Magnet Core using the same loading and constraint scenarios with good agreement on maximum deflections and stresses.

* T. Fornek is on loan from Argonne's Engineering Physics Division 

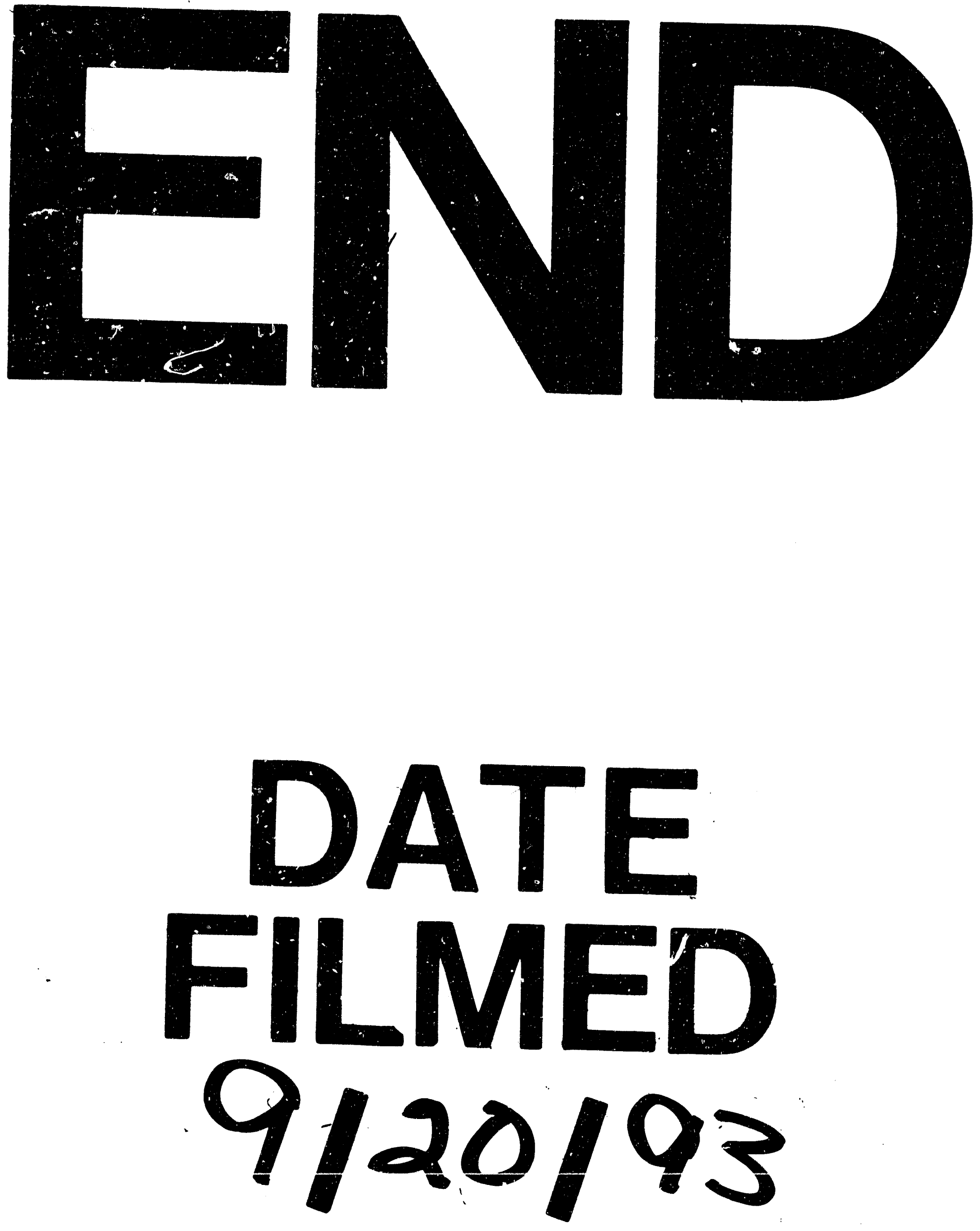
